${ }^{1} \mathrm{KM}$ Fischer*, ${ }^{2} \mathrm{H}$ Przepiera-Będzak, ${ }^{1}$ B Brzosko, ${ }^{3} \mathrm{M}$ Sawicki, ${ }^{2} \mathrm{M}$ Brzosko. ${ }^{1} /$ ndependent Laboratory for Rheumatologic Diagnostics, ${ }^{2}$ Department of Rheumatology, Internal Medicine and Geriatrics; ${ }^{3}$ Department of Imaging Diagnostics and Interventional Radiology, Pomeranian Medical University in Szczecin, Szzzecin, Poland

\subsection{6/annrheumdis-2018-EWRR2019.11}

Career situation of first and presenting author Assistant.

Introduction Vascular abnormalities are common complications in rheumatic patients. Their background is multifactorial and still is a subject of the debate.

Objectives This study was designed to evaluate the significance of selected noninvasive imaging indices, immunological and genetic biomarkers in diagnosis of vascular lesions in rheumatic diseases.

Methods The study group included 288 patients with systemic connective tissue diseases (SCTD).

The noninvasive evaluation of vascular lesions was made on the basis of carotid intima-media thickness (cIMT), ankle brachial index (ABI), high resistance index (HRI) and ulnar artery intraluminal diameter (UAID) measurements using HDI 3500 (ATL).

We analyzed more than 100 variables: autoantibodies, inflammatory and angiogenic markers, genetic polymorphisms and classical risk factors for atherosclerosis.

Statistical analysis was performed with STATA 11 including: chi ${ }^{2}$ Yates, chi ${ }^{2}$ Pearson and rank Spearman correlations tests, logistic regression analysis and multivariate stepwise analysis.

Results Macroangiopathy was influenced by selected autoantibodies including antiphospholipid ( $\mathrm{OR}=4.4 ; 95 \% \mathrm{CI}: 1.1-20.7)$ and anti-endothelial cell $(\mathrm{OR}=6.6 ; 95 \% \mathrm{CI}: 1.6-28.3)$ as well as inflammatory biomarkers $(\mathrm{OR}=3.6 ; 95 \% \mathrm{CI}: 1.1-11.8)$. The analysis of genetic polymorphisms showed especially an important impact of VEGF 2578 AA genotype on atherosclerosis development $(\mathrm{OR}=4.8 ; 95 \% \mathrm{CI}: 1.1-21.1)$. Angiogenic biomarkers were strongly associated with prothrombotic risk $(\mathrm{OR}=22.8 ; 95 \% \mathrm{CI}: 2.3-230.6)$. The analysis of relations between imaging indices and vascular manifestations revealed significant association of cIMT with cardiovascular $(\mathrm{OR}=52.9$; 95\% CI:7.0-1012.7) and cerebrovascular disease $(\mathrm{OR}=4.0$; 95\% CI:1.0-15.3). There was significant reverse correlation between $\mathrm{ABI}$ and peripheral vascular disease $(\mathrm{R}=-0.33$; $\mathrm{p}=0.001)$. HRI values significantly correlated with thromboembolic disorders $(\mathrm{R}=-0.29 ; \mathrm{p}=0.03)$. Finaly, UAID was notably related to microangiopathic complications $(\mathrm{p}<0.05)$.

Conclusions The protocol for vascular lesions diagnosis in SCTD should be based on the combination of imaging and laboratory biomarkers. Immunological and inflammatory factors are crucial in diagnostics of vascular involvement in rheumatic diseases. IMT and ABI showed a high prognostic value and can be used for the general cardiovascular risk stratification.

Disclosure of Interest None declared.

\section{P017 NON-ANTIBODY MEDIATED PATHOGENIC ROLES FOR SYNOVIAL B CELLS IN ACPA+ AND ACPA- RHEUMATOID ARTHRITIS}

${ }^{1}$ A Floudas ${ }^{*},{ }^{2} \mathrm{C}$ Low, ${ }^{1} \mathrm{M}$ Biniecka, ${ }^{2} \mathrm{DJ}$ Veale, ${ }^{1} \mathrm{U}$ Fearon. ${ }^{1}$ Trinity College Dublin; ${ }^{2} \mathrm{St}$. Vincent's Hospital, Dublin, Ireland

10.1136/annrheumdis-2018-EWRR2019.12
Career situation of first and presenting author Post-doctoral fellow. Introduction RF and ACPA have been used extensively for the diagnosis of RA, however no clear mechanism of action towards disease pathogenesis and progression has been identified. Importantly, both seropositive and seronegative RA patients experience significant improvement in disease severity following B cell depletion. Therefore, we hypothesized that B cells have a central role in $\mathrm{ACPA}^{+}$and $\mathrm{ACPA}^{-} \mathrm{RA}$ irrespective of their capacity to produce auto-antibodies.

Objectives To characterize $\mathrm{B}$ and $\mathrm{T}$ cell populations, their recruitment to the inflamed joint, $B$ cell cytokine production and $\mathrm{CD}^{+} \mathrm{T}$ cell polarization in RA synovial tissue biopsies and peripheral blood of $\mathrm{ACPA}^{+}, \mathrm{ACPA}^{-} \mathrm{RA}$ and arthralgia subjects. Methods Synovial tissue biopsies from $\mathrm{ACPA}^{+}$and $\mathrm{ACPA}^{-} \mathrm{RA}$ and $\mathrm{ACPA}^{+}$arthralgia subjects, with paired blood/synovial fluid, were obtained through key-hole arthroscopy and were enzymatically digested. $\mathrm{B}$ cell invasion assays and $\mathrm{B}$ and $\mathrm{CD} 4^{+}$ $\mathrm{T}$ cell in vitro stimulation were conducted under hypoxic conditions simulating the unique environment of the inflamed joint. Flow cytometric analysis was performed.

Results Significant accumulation, compared to peripheral blood, of pro-inflammatory B cells and pro-inflammatory cytokine-producing $\mathrm{CD}^{+} \mathrm{T}$ cells in the synovial tissue and fluid of RA patients, irrespective of ACPA status, as well as the synovial tissue of arthralgia subjects. SPICE analysis of peripheral blood B cells, for a panel of chemokine receptors, revealed a disease-specific expression pattern detected in RA and arthralgia subjects. Importantly, the tissue-invading B cells expressed CXCR3, with in vitro blockade of CXCR3 resulting in reduced $\mathrm{B}$ cell invasion in response to RA synovial tissue biopsy-conditioned media. Under the unique hypoxic conditions of the inflamed joint, RA patient but not healthy subject-derived $\mathrm{B}$ cells produce several pro-inflammatory cytokines including TNF-a and IL- 6 and are capable of polarizing CD4 ${ }^{+}$ $\mathrm{T}$ cells towards a pro-inflammatory phenotype.

Conclusions Accumulation of pro-inflammatory B cell subpopulations in the synovium of both $\mathrm{ACPA}^{+}$and $\mathrm{ACPA}^{-} \mathrm{RA}$ patients underlines a common, antibody-independent, contribution of B cells in synovial inflammation. Arthralgia early in disease, specific chemokine receptor expression and the accumulation of $\mathrm{CXCR}^{+} \mathrm{B}$ cells in the inflamed joint offers an opportunity for therapeutic intervention. Once in the hypoxic environment of the inflamed RA joint, B cells show altered activation, cytokine production and $\mathrm{T}$ cell polarization capacity that could prove important for understanding the role of $\mathrm{B}$ cells in disease pathogenesis of RA.

Disclosure of Interest None declared.

\section{P018 ANTI-CARBAMYLATED PROTEIN ANTIBODIES AS A CLINICAL RESPONSE PREDICTOR IN RHEUMATOID ARTHRITIS PATIENTS TREATED WITH ABATACEPT}

${ }^{1} \mathrm{M}$ Fredi* ${ }^{2}{ }^{2} \mathrm{M}$ Boldini, ${ }^{2} \mathrm{R}$ Kumar, ${ }^{1} \mathrm{~S}$ Piantoni, ${ }^{2} \mathrm{C}$ Cavazzana, ${ }^{3} \mathrm{E}$ Garrafa, ${ }^{2} \mathrm{C}$ Bazzani, ${ }^{1} \mathrm{~A}$ Tincani, ${ }^{1} \mathrm{~F}$ Franceschini. ${ }^{1}$ Rheumatology Unit and Department of Clinical and Experimental Sciences, Spedali Civili and University of Brescia; ${ }^{2}$ Rheumatology Unit, Spedali Civili of Brescia; ${ }^{3}$ Department of Molecular and Translational Medicine, University of Brescia, Brescia, Italy

\subsection{6/annrheumdis-2018-EWRR2019.13}

Career situation of first and presenting author Student for a master or a $\mathrm{PhD}$.

Introduction The presence of anti-carbamylated protein antibodies (anti-CarP) has been detected in rheumatoid arthritis 
(RA). ${ }^{1}$ Anti-CarP autoAbs target proteins that are modified through an irreversible post-translational modification named carbamylation.

Objectives The aim of this work was to assess whether antiCarP antibodies can be used as a predictive factor of clinical response to abatacept.

Methods Peripheral blood samples of selected patients were collected at the beginning of the therapy with abatacept (T0) and every six months for one year (T6 and T12). A homemade ELISA was applied to determine serum anti-CarP levels. Commercial anti-citrullinated protein antibodies (anti-CCP3) (Inova Diagnostic), Rheumatoid Factor (RF) (Siemens) and high sensitivity $\mathrm{C}$ reactive protein (hsCRP) were also tested.

Results Sixty RA patients (49 female (81.2\%)), all caucasian, treated with abatacept were enrolled. Fifty-three (88.3\%) and fifty-six $(93.3 \%)$ patients were also treated with corticosteroids and synthetic DMARD respectively. At baseline anti-CarP antibodies were found in 18 (30\%) patients; RF and anti-CCP were positive in $35(58 \%)$ and $51(85 \%)$ patients respectively. Comparing anti-CarP+ with anti-CarP- patients at T0, anti$\mathrm{CarP}+$ group resulted younger $(\mathrm{p}<0.01)$ and with a longer disease duration $(\mathrm{p}<0.05)$; hsCRP was higher in anti-CarP+ group $(p<0.05)$. Considering the entire cohort, a significant reduction of anti-CarP titre at T6 and T12 of treatment was shown $(\mathrm{p}<0.0001)$ while anti-CCP and RF titre did not show any significant change. Thirteen out of 18 patients anti-CarP+ were available for analysis at T6 and in 6 cases turned antiCarP-. A significant reduction of DAS28-CRP at T6 was found in the subgroup of anti-CarP+ pts in comparison with the negative ones $(p=0.03)$. No significant results were found dividing the cohort using the positivity to anti-CCP and/or RF. Furthermore, stratifying groups of patients for the combination of biomarkers, any groups including anti-CarP+ resulted in a trend towards a higher DAS28 reduction compared with the combination of anti-CCP+ and RF+ and antiCAP- ones.

Conclusions The precocious onset and a longer disease duration in anti-CarP positive patients might suggest them as a specific risk factors for RA in this subgroup of patients. The link between the anti-CarP positivity at baseline and the higher reduction of disease activity during the first six months of treatment permitted us to hypothesize that anti-CarP antibodies, but not anti-CCP and/or RF, could be a predictive factor of a good clinical response to abatacept.

\section{REFERENCE}

1. Shi J, et al. Proc Natl Acad Sci USA 2011;108(42):17372-7.

Disclosure of Interest None declared.

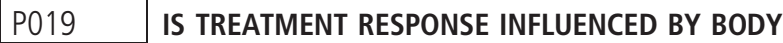 MASS INDEX IN JUVENILE IDIOPATHIC ARTHRITIS?}

${ }^{1} \mathrm{~T}$ Giani*, ${ }^{2} \mathrm{R}$ Cimaz. ${ }^{1}$ Rheumatology Unit, University of Florence and Siena; ${ }^{2}$ Rheumatology Unit, University of Florence, Florence, Italy

\subsection{6/annrheumdis-2018-EWRR2019.14}

Career situation of first and presenting author Student for a master or a $\mathrm{PhD}$.

Introduction There is evidence that obesity could be a risk factor for the severity and response to treatment in patients with RA due both to the mechanical effect of overweight and to the potential pro-inflammatory effects of cytokines produced by adipose tissue.

Objectives To evaluate the role of overweight and obesity in a cohort of patients with Juvenile Idiopathic Arthritis (JIA), in terms of incidence, disease activity, outcome and response to treatments.

Methods This single-center retrospective cohort study evaluated 110 children affected by JIA under treatment with antirheumatic agents (DMARDs, biologic agents). Changes from baseline in ESR, CRP, number of active joints, and BMI were analyzed under each treatment until last visit. BMI categories of 5-84th (normal weight), 85-94th (overweight), and $\geq 95$ th (obese) percentile were used. Patients with systemic JIA, uveitis, chronic comorbidities, or under other potentially confounding systemic treatments were excluded. Uni- and multivariate analyses were performed.

Results One hundred and ten JIA patients (polyarticular $n=50$, oligoarticular $n=38$, psoriatic $n=12$, enthesitis related arthritis $\mathrm{n}=8$, undifferentiated $\mathrm{n}=2$ ) were enrolled in the study, $75 \%$ girls, $25 \%$ boys. The mean age at treatment onset was 6.09 years. Baseline BMI was $\leq 84$ th percentile in 80 patients, $85-$ 94 th in 27 , and $\geq 95$ th in 3 .

We did not observe a significant association between BMI and ESR, CRP, or number of active joints at baseline, while involvement of the joints of lower limbs was significantly greater $(p=0.025)$ in overweight/obese patients. We observed a trend toward lower remission rates and higher number of relapses, both after DMARDs and biologics, in patients with higher BMI. Conclusions This study focuses on the relationship between overweight/obesity and JIA. A significant correlation between obesity and a greater involvement of the joints of the lower limbs was observed at baseline. Furthermore our data suggest that obesity could negatively influence the course of the disease as well as treatment response.

\section{REFERENCES}

1. Marques A, Peralta M, Naia A, Loureiro N, de Matos MG. Prevalence of adult overweight and obesity in 20 European countries. Eur J Public Health 2018;28:295-300.

2. Liu Y, Hazlewood GS, Kaplan GG, Eksteen B, Barnabe C. The impact of obesity on remission and disease activity in rheumatoid arthritis: a systematic review and meta-analysis. Arthritis Care Res (Hoboken) 2017;69:157-65.

3. CF Pelajo, JM Lopez-Benitez, LC Miller. Obesity and disease activity in juvenile idiopathic arthritis. Pediatr Rheumatol 2012;10:3

Disclosure of Interest None declared.

\section{P021 DIFFERENTIAL ACPA BINDING TO NUCLEAR ANTIGENS REVEALS A DISTINCT SUBSET OF ACETYLATION CROSS-REACTIVE AUTOANTIBODIES IN RHEUMATOID ARTHRITIS}

${ }^{1,2} \mathrm{G}$ Wigerblad, ${ }^{1} \mathrm{KA}$ Lloyd, ${ }^{1,3} \mathrm{P}$ Sahlström, ${ }^{1} \mathrm{E}$ Ossipova, ${ }^{1} \mathrm{~K}$ Chemin, ${ }^{1} \mathrm{~S}$ Steen, ${ }^{1,4} \mathrm{PJ}$ Titcombe, ${ }^{1} \mathrm{D}$ Zhou, ${ }^{1} \mathrm{R}$ Stålesen, ${ }^{5} \mathrm{~J}$ Rönnelid, ${ }^{4} \mathrm{DL}$ Mueller, ${ }^{2} \mathrm{MJ}$ Kaplan, ${ }^{3} \mathrm{~K}$ Skriner, ${ }^{1} \mathrm{~L}$ Klareskog, ${ }^{1} \mathrm{~F}$ Wermeling, ${ }^{1} \mathrm{~V}$ Malmström, ${ }^{1} \mathrm{C}$ Grönwall*. ${ }^{1}$ Division of Rheumatology, Dept. of Medicine, Karolinska Institutet, Stockholm, Sweden; ${ }^{2}$ Systemic Autoimmunity Branch, Intramural Research Program, National Institute of Arthritis and Musculoskeletal and Skin Diseases, National Institutes of Health, Bethesda, USA; ${ }^{3}$ Dept. of Medicine, Charité University Hospital, Berlin, Germany; ${ }^{4}$ The Center for Immunology, University of Minnesota Medical School, Minneapolis, USA; ${ }^{5}$ Dept. of Immunology, Genetics and Pathology, Uppsala University, Uppsala, Sweden

\subsection{6/annrheumdis-2018-EWRR2019.15}

Career situation of first and presenting author Young investigator. 